\title{
Antimicrobial Activity of a Novel Secondary Metabolite from Streptomyces sp. and Molecular Docking Studies against Bacterial Leaf Blight Pathogen of Rice
}

\author{
Nanjundan Jaivel $^{1 *}$, Ramasamy Rajesh ${ }^{1}$, Devadasan Velmurugan ${ }^{2}$ and \\ Ponnusamy Marimuthu ${ }^{1}$ \\ ${ }^{1}$ Department of Agricultural Microbiology, Tamil Nadu Agricultural University, \\ Coimbatore, 641 003, Tamil Nadu, India \\ ${ }^{2}$ Department of Crystallography and Biophysics, University of Madras, \\ Chennai, 600 025, Tamil Nadu, India \\ *Corresponding author
}

\section{A B S T R A C T}

\section{Keywords}

Streptomyces sp.,

Antimicrobial, Xoo,

MIC, Docking, 2-(1,1-

diallyl-but-3-enyl)-5-

nonyl-phenol.

Article Info

Accepted:

20 September 2017

Available Online:

10 November 2017
The metabolite 2-(1,1-diallyl-but-3-enyl)-5-nonyl-phenol isolated from Streptomyces sp. TC1 exhibited antimicrobial activity against bacterial leaf blight pathogen Xanthomonas oryzae pv. oryzae (Xoo). The in vitro antimicrobial activity was found to be between $1.8-2.5 \mathrm{~cm}$ in agar well diffusion assay against the tested Xoo isolates and $200 \mu \mathrm{g} / \mathrm{ml}$ in terms of minimum inhibitory concentration. The isolated compound showed well binding with the virulence proteins of Xoo by producing a better docking score in molecular docking studies.

\section{Introduction}

Bacterial leaf blight (BLB) of rice, caused by Xanthomonas oryzae pv. oryzae (Xoo) is one of the oldest known diseases and was first noticed by the farmers of Japan in 1884 . Subsequently, its incidence has been reported from different parts of Asia, northern Australia, Africa and USA (Gnanamanickam, 2002). The disease is known to occur in epidemic proportions in many parts of the world, incurring severe crop loss of up to 50\%. Crop loss assessment studies have revealed that this disease reduces grain yield to varying levels, depending on the stage of the crop, degree of cultivar susceptibility and to a great extent, the conduciveness of the environment in which it occurs (Muralidharan and Venkatarao, 1979). Over 55\% of antibiotics have been isolated from genus Streptomyces and therefore this genus is one of the several biological control agents which are widely studied and used to control various plant pathogens (Embley and Stackebrandt, 1994). Many of the seed, soil-borne and foliar diseases were efficiently managed by biocontrol means using Bacillus sp. Pseudomonas sp. Streptomyces sp. and 
Trichoderma sp. A numbers of antimicrobial metabolites were produced by these strains which have different mode of actions in suppression of plant pathogens.

Recent studies revealed the antimicrobial action of some Streptomycetes against plant pathogens including Xoo (Ndonde and Semu, 2000; Rizk et al., 2007). Park et al., (2011) reported the suppression of bacterial blight pathogen by the compounds isolated from Streptomyces bottropensis sp. viz., bottromycin A2 and dunaimycin D3S. Xanthostatin is a novel depsipeptide antibiotic produced by Streptomyces spiroverticillatus (Cheng et al., 1987) has bacteriostatic activity against Xanthomonas sp.

Molecular modeling is more important in cellular biology to study the interaction between the proteins and also with other molecular components. The molecular docking is also used to predict the action of drugs against specific diseases. Knowledge of the preferred orientation in turn may be used to predict the strength of association or binding affinity between two molecules using scoring functions. Xoo has so many virulence proteins like Lip A, XoFabV, Fab H, Xoo2316, XometC, XoMCAT, XometB, Xoo0352, GlmU etc. These virulence factors are responsible for establishment of bacterial leaf blight disease in rice. The type II protein secretion system (T2S) of Xoo involved in secretion of several protein including xylanase required for its virulence function (Ray et al., 2000). By studying the interaction of molecular components against these virulence proteins the possible antimicrobial spectrum can be obtained.

In this present study the novel compound 2(1,1-diallyl-but-3-enyl)-5-nonyl-phenol isolated from Streptomyces sp. TC1 (Jaivel et al., 2014) was analyzed for their antimicrobial activity against Xanthomonas oryzae pv. oryzae and their molecular docking results with Xoo specific virulence proteins were also reported.

\section{Materials and Methods}

\section{Microbial culture}

The Streptomyces sp. TC1 (GenBank accession number: KC954629) was grown in Ken knight agar slants for five days at $28^{\circ} \mathrm{C}$ and maintained under refrigerated conditions. The test culture Xanthomonas oryzae pv. oryzae $(\mathrm{Xoo})$ from various sources were obtained from the Department of Plant Pathology, Tamil Nadu Agricultural University, Coimbatore, India.

\section{Fermentation and isolation}

A seed culture of Streptomyces sp. TC1 was prepared by inoculating a loop of biomass into a $200 \mathrm{ml}$ Erlenmeyer flask containing $100 \mathrm{ml}$ of Ken knight broth and then incubating at $28{ }^{\circ} \mathrm{C}$ for 3 days. A $10 \%$ level of this inoculum was transferred into $1000 \mathrm{ml}$ of production medium contained in 31 Erlenmeyer flasks (15 in number). The production medium having the composition of soluble starch $1.0 \%$, casein $0.03 \%, \mathrm{KNO}_{3}$ $0.2 \%, \mathrm{NaCl} 0.2 \%, \mathrm{~K}_{2} \mathrm{HPO}_{4} 0.2 \%, \mathrm{CaCO}_{3}$ $0.002 \%, \quad \mathrm{MgSO}_{4} .7 \mathrm{H}_{2} \mathrm{O} \quad 0.005 \%$ and $\mathrm{FeSO}_{4} .7 \mathrm{H}_{2} \mathrm{O} \quad 0.001 \%$ with $\mathrm{pH}$ 8.0. The inoculated production flasks were incubated for 7 days at $28^{\circ} \mathrm{C}$. After the fermentation period, the metabolite 2-(1,1-diallyl-but-3enyl)-5-nonyl-phenol isolated from the fermentation broth by standard solvent extraction and column chromatographic separation procedure (Jaivel et al., 2014).

\section{Screening of antimicrobial activity}

In vitro antimicrobial activity was studied against various isolates of Xoo strains by agar well diffusion method (Perez et al., 1990). 
The metabolite was diluted in $100 \%$ ethanol at the concentration of $1 \mathrm{mg} / \mathrm{ml}$. The antimicrobial activity was evaluated by loading $50 \mu \mathrm{l} /$ well. The standard antibiotic streptomycin used as a positive control at the concentration of $1 \mathrm{mg} / \mathrm{ml}$. The antimicrobial spectrum was determined in terms of zone of inhibition.

Ethanol was used as negative control. The control zones were subtracted from the test zones and the results are arrived. The minimum inhibitory concentration (MIC) assay was performed to test the antimicrobial activity using modified version of broth microdilution method recommended by NCCLS (National Committee for Clinical Laboratory Standards, 2000).

\section{Docking studies}

Docking is a methodology used in molecular modeling to predict the preferred orientation of one molecule to a second when bound to each other to form a stable complex in three dimensional spaces. The bioinformatics Software used for the docking study was "GLIDE". The target enzymes/ template proteins used for docking studies were cell wall-degrading esterase (Lip A, PDB I.D.: $3 \mathrm{H} 2 \mathrm{G}$ ), enoyl-ACP reductase (Fab V, PDB I.D.: 3S8M), D-alanine-d-alanine ligase A (DdlA, PDB I.D. 3R5F) and peptide deformylase (PDF, PDB I.D. 3DLD).

All of these were virulence protein secreted by Xanthomonas oryzae pv. oryzae at different stages of bacterial blight disease development in rice. The details of the target proteins were obtained from Protein Data Bank (PDB) database. The docking work was carried out at Centre for Advanced Studies in Crystallography and Biophysics, University of Madras. The best docking scores indicates the strong binding of the molecule with the protein.

\section{Induced fit docking}

Induced Fit Docking studies was carried out using GLIDE (Singh and Randhawa, 2011) software v5.5, developed by Schrodinger, running on Red Hat Enterprise Linux 5 (RHEL5) workstation and Maestro v9.0. Graphical User Interface (GUI) workspace was used for all the steps involved in ligand preparation, protein preparation and Induced Fit Docking (IFD).

\section{Preparation of the ligand}

The ligand used in this study was prepared using Ligprep module of v2.3 of Schrodinger Suite 2009. Ligprep follows OPLS-AA (Optimized Potential Liquid Simulations for All Atoms) force fields for energy minimization. The proteins taken for the study was retrieved from PDB (Protein Data Bank) database.

The optimized structure was then energy minimized to remove the steric clashes between the atoms. The energy minimization was done till it reached a Root Mean Square Deviation (RMSD) cutoff of $0.18{ }^{\circ} \mathrm{A}$ and the resulting structure was used for docking (Vinuchakkaravarthy et al., 2011).

\section{Induced Fit Docking (IFD) protocol}

IFD of the prepared ligand with the prepared protein was performed using IFD protocol of GLIDE v5.5 from Schrodinger Suite 2009 (Vinuchakkaravarthy et al., 2011). Both the ligand and the receptor were flexible which enabled the ligand to dock at the receptor's binding site and generate multiple poses of the receptor-ligand complex. Each docking included unique structural conformations of the receptor needed to fit the ligand pose. The IFD gave the best structure of the docked complex based on the Glide score (G-score) of the dockings. 


\section{Visualization and analysis}

The hydrophobic interactions and hydrogen bond interactions were obtained as ligplot diagram by submitting the docked complexes to the online PDB sum server http://www.ebi.ac.uk/pdbsum/.

\section{Results and Discussion}

\section{Antimicrobial activity of 2-(1,1-diallyl-but-} 3-enyl)-5-nonyl-phenol against various isolates of $\mathrm{XoO}$

The antimicrobial activity in terms of zone of inhibition against various isolates of Xoo was carried out for 2-(1,1-diallyl-but-3-enyl)-5nonyl-phenol. The compound produced a zone of inhibition of $1.8-2.5 \mathrm{~cm}$ against the tested Xoo isolates (Table 1). The highest activity of $2.5 \mathrm{~cm}$ inhibition zone was found against the Xoo isolate obtained from TN1 variety (Fig. 1). Whereas the lowest activity of $1.8 \mathrm{~cm}$ zone of inhibition was observed for Xoo isolate obtained from CO50 variety. The MIC experiments carried out using NCCLS protocol showed that the isolated compound exhibited an MIC value of $200 \mu \mathrm{g} / \mathrm{mL}$ against the tested Xoo isolate.

\section{Docking studies}

The antimicrobial compounds inhibit the growth of bacteria by several mechanisms like cell wall inhibition, protein synthesis inhibition, inhibition of DNA synthesis etc. In the present study the possible mode of action of isolated antimicrobial compound was analyzed by molecular docking studies. Docking studies were performed to predict the preferred orientation of isolated molecule to the selected virulence protein of Xoo which bound to each other to form a stable complex. The binding strength of the isolated molecule against the tested virulence proteins was also predicted.

\section{Induced fit docking results with the target} proteins

Docking was performed for 2-(1,1-diallyl-but3-enyl)-5-nonyl-phenol with 4 target proteins namely Lip A, Fab V, Ddl A and PDF. The docking score and glide energy of compound with the respective target proteins was given in Table 2. The lower docking score indicates better docking of compound with the desired proteins. The compound with Lip A obtained the Glide energy of -54.46 with a docking score of $-11.98 \mathrm{kcal} \mathrm{mol}^{-1}$ and there was 1 hydrogen bond interaction with ASN 228 (Fig. 2). Likewise, the compound with Fab V obtained the Glide energy of -42.65 with a docking score of $-8.11 \mathrm{kcal} \mathrm{mol}^{-1}$. There was 1 hydrogen bond interaction with THR 276 (Fig. 3). The compound with Ddl A obtained the Glide energy of -36.36 with a docking score of $-3.52 \mathrm{kcal} \mathrm{mol}^{-1}$.

There was 1 hydrogen bond interaction with GLU 228 (Fig. 4). The compound with PDF obtained the Glide energy of -41.22 with a docking score of $-5.94 \mathrm{kcal} \mathrm{mol}^{-1}$. There were 1 hydrogen bond interactions with TYR 69 (Fig. 5).

Among the four target proteins, Lip A was found to be possess more binding towards the compound (Fig. 6) followed by Fab V. Hence it was determined from this hypothetical way that compound binds well with rice cell wall degrading protein and thus prevents systemic infection caused by the entry of Xoo.

\section{Antimicrobial activity of isolated compounds against $\mathrm{Xoo}$ isolates}

The improved rice varieties released in India, though having a certain degree of resistance to bacterial blight became susceptible due to emergence of new races of the pathogen (Khush et al., 1989). In the present study, the isolated compound produced an inhibition 
zone of $1.8-2.5 \mathrm{~cm}$ in terms of zone of inhibition against the tested Xoo isolates. The Xoo isolate from $\mathrm{TN} 1$ rice variety showed increased susceptibility, whereas the isolated compound produced a moderate inhibition zone against Xoo isolate obtained from $\mathrm{CO} 50$ rice variety.

The variation may be due to the different levels of susceptibility to the antimicrobial compounds by various isolates of Xoo. This was supported by Leach et al., (1995), who reported that the Xoo pathotypes posses varied levels of susceptibility to antimicrobial compounds due to their resistance genes.
Larrainzar et al., (2012) reported the antimicrobial and antioxidant activities of many phenolic compounds isolated from natural sources. In the present study, the highest antimicrobial potential of compound was observed against Xoo due to the presence of phenol and diallyl moiety in its structure. Similarly the antimicrobial action of natural phenolic compounds against the gram negative bacteria Enterococcus faecalis was reported by Fernandez et al., (2013). Further Tsao and Yin (2001) reported the antimicrobial activity of diallylsulphide against methicilin resistant Staphylococcus aureus.

Table.1 Antimicrobial activity of 2-(1,1-diallyl-but-3-enyl)-5-nonyl-phenol against Xoo

\begin{tabular}{lc}
\hline Source of Xoo isolate & Diameter of inhibition zone (in cm) \\
\hline TN 1 & $2.5 \pm(0.12)$ \\
TNRH 180 & $2.2 \pm(0.10)$ \\
CO 47 & $2.1 \pm(0.06)$ \\
CO 50 & $1.8 \pm(0.15)$ \\
ADT 39 & $2.2 \pm(0.06)$ \\
ADT 43 & $2.0 \pm(0.12)$ \\
\hline SEd & 0.086 \\
CD $(.05)$ & 0.188 \\
\hline
\end{tabular}

Values are mean \pm SD of three replicates

Table.2 Induced fit docking results of 2-(1,1-diallyl-but-3-enyl)-5-nonyl-phenol with the target proteins

\begin{tabular}{|c|c|c|c|c|c|c|c|}
\hline $\begin{array}{l}\text { Sl. } \\
\text { No. }\end{array}$ & $\begin{array}{c}\text { Target } \\
\text { protein }\end{array}$ & $\begin{array}{c}\text { PDB } \\
\text { ID }\end{array}$ & $\begin{array}{c}\text { Docking } \\
\text { Score }\end{array}$ & $\begin{array}{c}\text { Glide } \\
\text { Energy } \\
\text { (kcal/mol) }\end{array}$ & $\begin{array}{l}\text { Number of } \\
\text { hydrogen } \\
\text { bonds }\end{array}$ & Interaction & $\begin{array}{c}\text { Distance } \\
\text { (ঐ) }\end{array}$ \\
\hline 1. & Lip A & $3 \mathrm{H} 2 \mathrm{G}$ & -11.98 & -54.46 & 1 & $(\mathrm{ASN} 228) \mathrm{O}-\mathrm{H} \cdot \mathrm{OO}$ & 3.1 \\
\hline 2. & Fab V & $3 \mathrm{~S} 8 \mathrm{M}$ & -8.11 & -42.65 & 1 & $(\mathrm{THR} 276) \mathrm{O}-\mathrm{H} \cdot \cdots \mathrm{O}$ & 2.9 \\
\hline 3. & Ddl A & 3R5F & -3.52 & -36.36 & 1 & (GLU 228) O-H ‥ & 2.7 \\
\hline 4. & $\mathrm{PDB}$ & 3DLD & -5.94 & -41.22 & 1 & (TYR 69) O-H. O & 2.9 \\
\hline
\end{tabular}


Fig.1 Antimicrobial activity of 2-(1,1-diallyl-but-3-enyl)-5-nonyl-phenol against Xoo

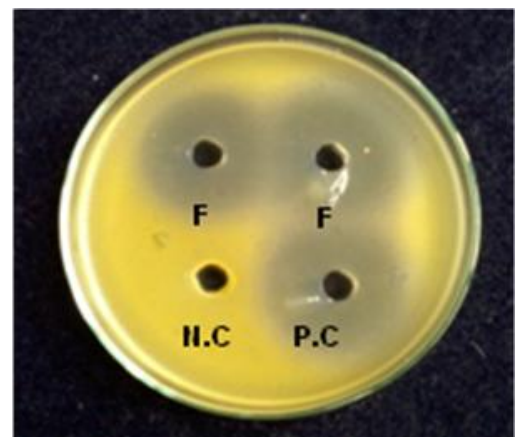

F- 2-(1,1-diallyl-but-3-enyl)-5-nonyl-phenol

N.C. - Negative control (100\% ethanol)

P.C. - Positive control (Streptomycin)

Fig.2 Docking of 2-(1,1-diallyl-but-3-enyl)-5-nonyl-phenol with esterase LipA protein (PDB I.D. 3H2G)

\section{Docked complex}

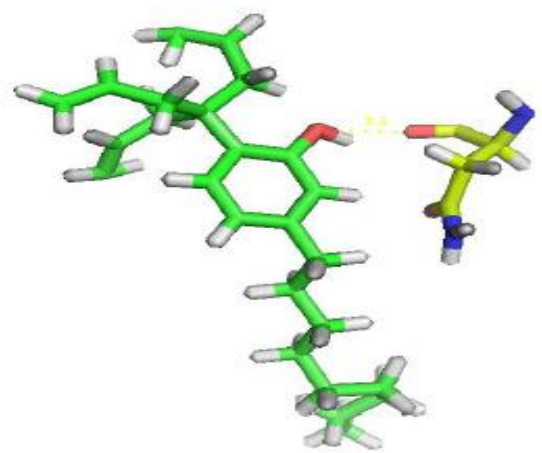

Ligplot image

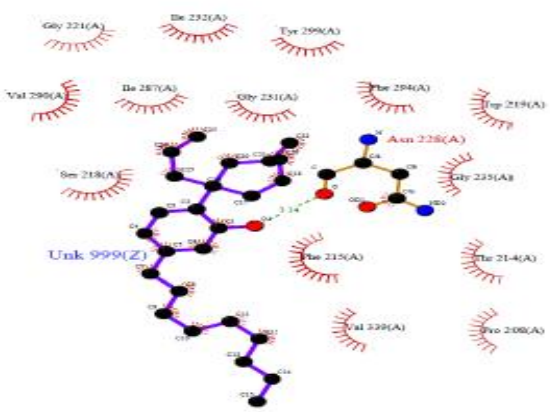

Fig.3 Docking of 2-(1,1-diallyl-but-3-enyl)-5-nonyl-phenol with Enoyl-ACP reductase (FabV) protein (PDB I.D. 3S8M)

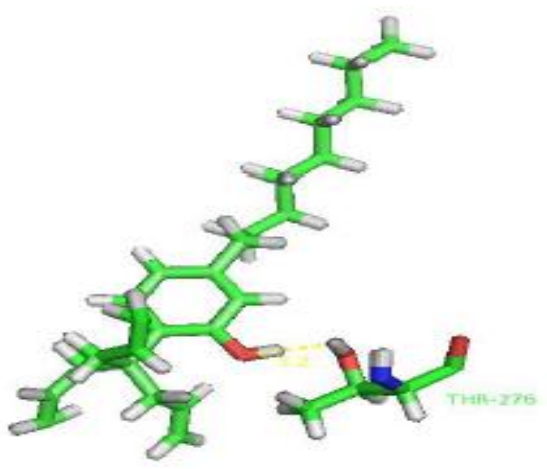

Docked complex

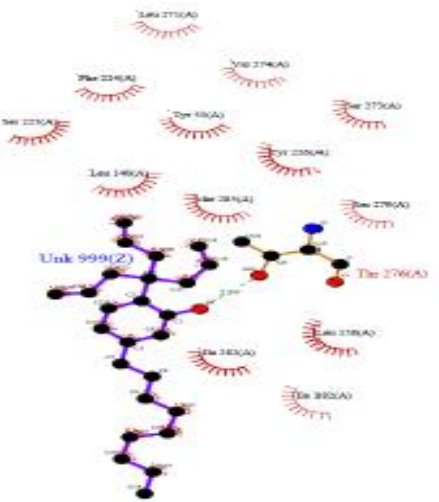

Ligplot image 
Fig.4 Docking of 2-(1,1-diallyl-but-3-enyl)-5-nonyl-phenol with D-alanine-d-alanine ligase A (DdlA) protein (PDB I.D. 3R5F)

Docked complex

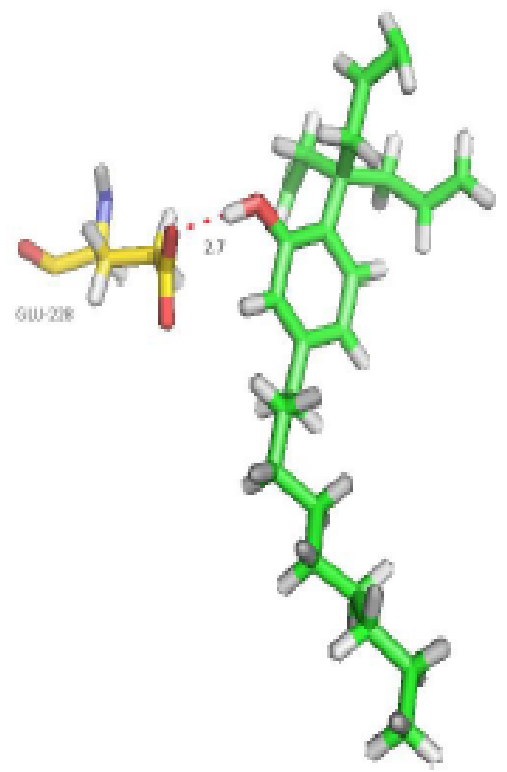

Ligplot image

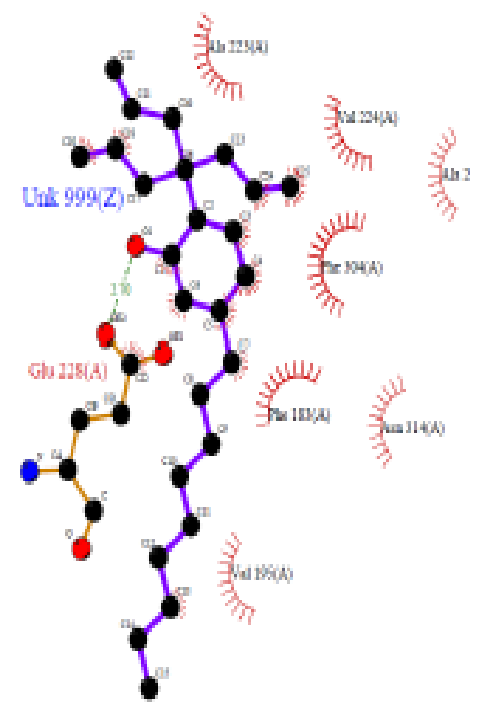

Fig.5 Docking of 2-(1,1-diallyl-but-3-enyl)-5-nonyl-phenol with Peptide deformylase (PDF) protein (PDB I.D. 3DLD)

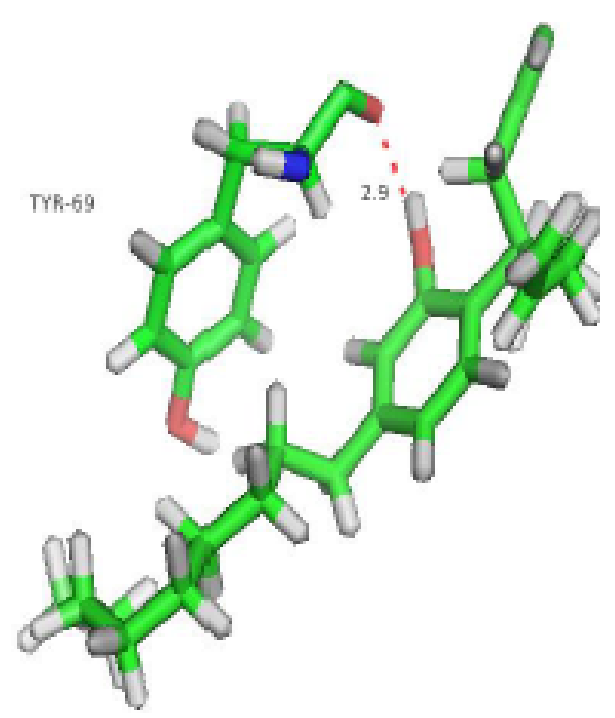

Docked complex

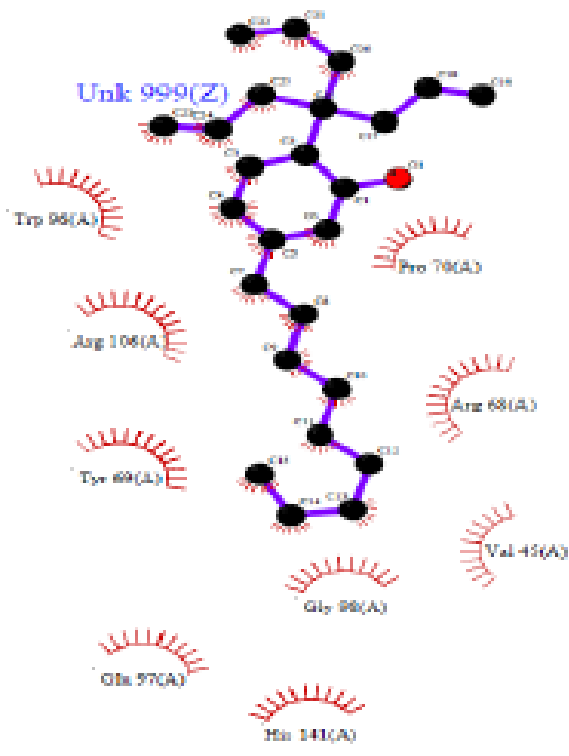

Ligplot image 
Fig.6 Docking score and glide energy of 2-(1,1-diallyl-but-3-enyl)-5-nonyl-phenol with target proteins

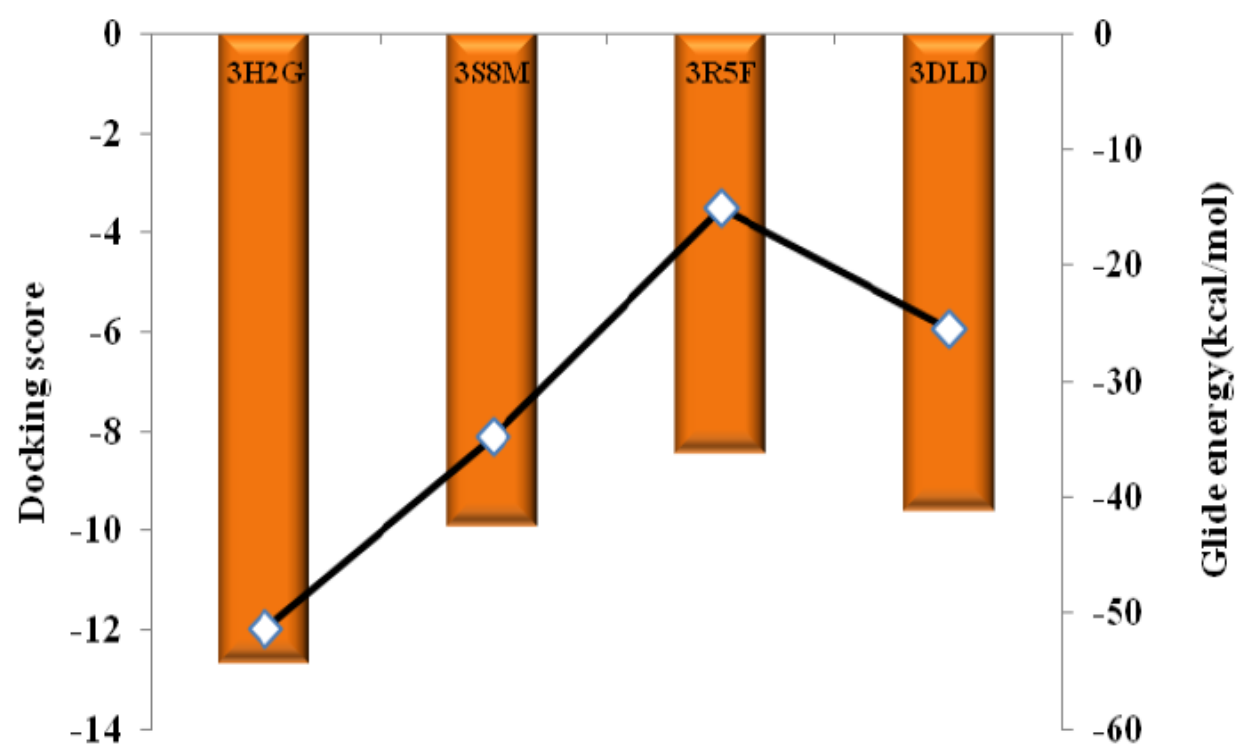

Glide energy $(\mathrm{kcal} / \mathrm{mol}) \quad->$ Docking score

Possible mode of action of isolated antimicrobial metabolites

Understanding the mode of action is a preliminary approach to study the properties of any bioactive molecules. The antimicrobial compounds can affect microbial cells by several ways including cell wall synthesis inhibition, cytoplasmic membrane damage, inhibition of specific enzyme system, inhibition of nucleic acid and protein synthesis etc. In this present study the isolated molecules are studied for their possible mode of action by molecular docking studies. The aim of molecular docking is to achieve an optimized conformation for both the protein and ligand and relative orientation between protein and ligand (Kitchen et al., 2004).

The docking is a method which predicts the preferred orientation of one molecule with other one when bound to each other to form a stable complex. Docking small, mostly organic compounds to proteins is relevant to both understanding biological processes and designing drugs. In the past 25 yrs a large set of different methods have been developed for screening the databases of ligands and accurately analyzing individual molecular interactions (Thomas and Matthias, 1996).

Hughes et al., (1990) reported that molecular docking is a key tool in structural molecular biology and computer-assisted drug design. The goal of ligand-protein docking is to predict the predominant binding model(s) of a ligand with a protein of known threedimensional structure. Shanthi et al., (2011) carried out docking studies for an antimicrobial compound isolated from cow urine extract of Pongamia pinnata against four different virulence proteins of Xoo. The antimicrobial compound dihydropyranoflavanoid produce an binding energy of -7.87 , - 6.67, -6.45, - $7.98 \mathrm{kcal} / \mathrm{mol}$ against Malonyl CoA-ACP transacylase, D-Alanine-d-alanine ligase A, 3-oxoacyl-(acyl carrier protein) synthase III and $\mathrm{N}$-acetylornithine 
transcarbamylase respectively. The target enzymes are mainly involved in fatty acid metabolism and peptidoglycan biosynthesis. A number of 1-4 hydrogen bonds are formed between the ligand and protein complex.

In this present study the isolated antimicrobial compound was docked against four different virulence proteins of Xoo. The compound exhibited good binding potential with Fab V protein responsible for fatty acid elongation cycle during cell wall synthesis and Lip A protein responsible for rice cell wall degradation. Whereas, binding of isolated compound with peptide deformylase (PDF) and D-alanine-d-alanine-ligase A (Ddl A) was found to be low compared to other two proteins studied. Hence, the compounds might have less influence on inhibiting the protein and DNA synthesis machinery.

This was also supported by poor binding of 2(1,1-diallyl-but-3-enyl)-5-nonyl-phenol with CT-DNA in previously conducted DNA binding experiments (Jaivel et al., 2014). As the compound binds well with the Lip A protein which is an extracellular esterase aids in rice cell wall degradation, thus the systemic infection of Xoo can be prevented at entry level itself. Whereas the isolated compounds bind well with good docking score against Fab V protein, thereby it is inferred that the compounds might have the property of cell wall inhibition of target pathogen.

\section{References}

Cheng, X.C, Kihara, T, Kusakabe, H, Fang, R.P, Ni， Z.F, Shen, Y.C, Ko, K.I, Yamaguchi and Isono, K. 1987. Xanthostatin, a new antibiotic. Agric. Biol. Chem., 51: 279-281.

Embley, T.M and Stackebrandt, E. 1994. The molecular phylogeny and systematics of the actinomycetes. Ann. Rev. Microbiol., 48: 257-289.
Fernandez, J.G, Garcia-Armesto, M.R, Alvarez-Alonso, R, Del Valle, P, D. De Arriaga and Rua, J. 2013. Antimicrobial activity of binary combinations of natural and synthetic phenolic antioxidants against Enterococcus faecalis. J. Dairy Sci., 96: 4912-4920.

Gnanamanickam, S.S. 2002. Biological Control of Crop Diseases. Marcel Dekker Inc., New York, pp. 468.

Hughes, L.R, Jackman, A.L, Oldfield, J, Smith, R.C, Burrows, K.D, Marsham, P.R, Bishop, J.A, Jones, T.R, B.M. O'Connor and Calvert, A.H. 1990. Quinazoline antifolate thymidylate synthase inhibitors: alkyl, substituted alkyl and aryl substituents in the $\mathrm{C} 2$ position. J. Med. Chem., 33: 3060-3067.

Jaivel, N, Uvarani, C, Rajesh, R, D. Velmurugan and Marimuthu, P. 2014. Natural occurrence of organofluorine and other constituents from Streptomyces sp. TC1. J. Nat. Prod., 77 (1): 2-8.

Khush, G.S, D.J. Mackill and Sidhu, G.S. 1989. Breeding rice for resistance to bacterial blight. In: Proceedings of international workshop on bacterial blight of rice, IRRI, Philippines, pp. 207-217.

Kitchen, D.B, Decornez, H, J.R. Furr and Bajorath, J. 2004. Docking and scoring in virtual screening for drug discovery: methods and applications. Nature Rev. Drug Disc., 3(11): 935-949.

Larrainzar, G.M, Rua, J, Caro, I, De Castro, C, De Arriaga, D, M.R. Garcia-Armesto and Del Valle, P. 2012. Evaluation of antimicrobial and antioxidant activities of natural phenolic compounds against food borne pathogens and spoilage bacteria. Food Control, 26: 555-563.

Leach, J.E, Leung, H, R.J. Nelson and Mew, T.W. 1995. Population biology of Xanthomonas oryzae pv. oryzae and approaches to its control. Curr. Opin. 
Biotechnol., 6: 298-304.

Muralidharan, K and Venkatarao, G. 1979. Bacterial blight (Xanthomonas campestris pv. oryzae) on rice in Nellore district, Andhra Pradesh, India. Indian Phytopathol, 32: 483-485.

NCCLS. 2000. Methods for dilution antimicrobial susceptibility tests for bacteria that grow aerobically. Approved Standard, $5^{\text {th }}$ ed. NCCLS document M7-A5, National Committee for Clinical Laboratory Standards, Wayne, Pa.

Ndonde, M.J.M and Semu, E. 2000. Preliminary characterization of some Streptomyces species from four Tanzanian soils and their antimicrobial potential against selected plant and animal pathogenic bacteria. World $J$. Microbiol. Biotechnol., 16: 595-599.

Park, S.B, I.A. Lee and Suh, J.W. 2011. Screening and identification of antimicrobial compounds from Streptomyces bottropensis suppressing rice bacterial blight. J. Microbiol. Biotechnol., 21(12): 1236-42.

Perez, C, M. Paul and Bazerque, P. 1990. An antibiotic assay by the agar well diffusion method. Acta Biol. Med. Exp., 15: 113-115.

Ray, S.K, R. Rajeshwari and Sonti, R.V. 2000. Mutants of Xanthomonas oryzae pv. oryzae deficient in general secretory pathway are virulence deficient and unable to secrete xylanase. Mol. Plant Microbe Interact, 13: 394-401.

Rizk, M, R.T. Abdel and Metwally, H. 2007. Screening of antagonistic activity in different Streptomyces species against some pathogenic microorganisms. $J$. Biol. Sci., 7: 1418-1423.

Shanthi, S, C. Thiyagarajan and Panneerselvam, A. 2011. In silico docking investigation of DHPF compound isolated from cow urine extract of Pongamia pinnata Linn against Xanthomonas species. J. Pharm. Res., 4: 4199-4201.

Thomas, L and Matthias, R. 1996. Computational methods for biomolecular docking. Curr. Opin. Struct. Biol., 6: 402-406.

Tsao, S.M and Yin, M.C. 2001. In vitro antimicrobial activity of four diallyl sulphides occurring naturally in garlic and Chinese leek oils. J. Med. Microbiol., 50: 646-649.

Vinuchakkaravarthy, T, Kumaravel, K.P, S. Ravichandran and Velmurugan, D. 2011. Active compound from the leaves of Vitex negundo L. shows antiinflammatory activity with evidence of inhibition for secretory phospholipase A2 through molecular docking. Bioinformation, 7(4): 199-206.

\section{How to cite this article:}

Nanjundan Jaivel, Ramasamy Rajesh, Devadasan Velmurugan and Ponnusamy Marimuthu. 2017. Antimicrobial Activity of a Novel Secondary Metabolite from Streptomyces sp. and Molecular Docking Studies against Bacterial Leaf Blight Pathogen of Rice. Int.J.Curr.Microbiol.App.Sci. 6(11): 2861-2870. doi: https://doi.org/10.20546/ijcmas.2017.611.337 